https://helda.helsinki.fi

\title{
Parental care amplifies changes in offspring production in a disturbed environment
}

\section{Candolin, Ulrika}

2021-12

Candolin , U , Goncalves , S \& Pant , P 2021 , ' Parental care amplifies changes in offspring production in a disturbed environment ' , Oikos , vol. 130 , no. 12 , pp. 2231-2238 . https://doi.org/10.1111/oik.08668

http://hdl.handle.net/10138/336984

https://doi.org/10.1111/oik.08668

unspecified

submittedVersion

Downloaded from Helda, University of Helsinki institutional repository.

This is an electronic reprint of the original article.

This reprint may differ from the original in pagination and typographic detail.

Please cite the original version. 


\title{
Parental care amplifies changes in offspring production in a disturbed environment
}

\author{
Ulrika Candolin, Sara Goncalves and Pankaj Pant \\ Organismal and Evolutionary Biology, University of Helsinki, Finland
}

Author for correspondence: Ulrika Candolin, e-mail: ulrika.candolin@helsinki.fi orcid.org/0000-0001-8736-7793

\begin{abstract}
Recruitment is usually negatively density-dependent with fewer offspring surviving when more are produced. Parental care could alter the pattern as behaviours that maximize individual fitness are not necessarily adaptive at the population level. We manipulated the number of eggs spawned into the nests of male threespine stickleback, and found egg survival to be positively densitydependent. This reversed negative density-dependent survival observed in the absence of parental care. The reversal was caused my males investing more in parental care when receiving more eggs, while favouring future reproductive opportunities when receiving few eggs. Densitydependent parental care thus amplified changes in offspring production in relation to number of eggs spawned. Such amplification may occur in disturbed environments where human activities have altered female fecundity and males may receive more or less eggs than expected. The optimal balancing between present and future parental investment can then be distorted, resulting in maladaptive parental behaviour that reduces offspring survival. These results suggest that behaviours that have evolved to maximize individual fitness under pristine conditions can become mal-adaptive under disturbed conditions and influence the recruitment of offspring into a population. Considering that human activities are rapidly transforming environments, such maladaptive behavioural responses could be common and magnify negative effects of human activities on population dynamics.
\end{abstract}

Key words: Early-life effects, fecundity, hatching success, parental effects, recruitment, reproduction 


\section{Introduction}

Unravelling the factors that regulate population growth is an important endeavour in our increasingly disturbed world. Processes during early life are especially important in this respect, as they determine the proportion of offspring that reach maturity. Negative density-dependent survival, through the competition for limited resources, regulates recruitment in many populations (Murdoch 1994, Rose et al. 2001, Turchin 1995). However, a factor that could influence this pattern, but has received little attention, is the impact of parental care. Parents may adjust their investment into care depending on environmental conditions, the expected viability of the offspring, and future reproductive opportunities, which could influence recruitment (AlonsoAlvarez and Velando 2012, Klug et al. 2012, Ratikainen et al. 2018). Behaviours have evolved to maximize individual fitness, not population viability or stability (Anthony and Blumstein 2000, Frank 2010), and may become maladaptive also at the individual level when the environment changes (Sih et al. 2011, Tuomainen and Candolin 2011). Yet, the impact that individual behavioural decisions have on population dynamics in disturbed environments are still poorly known (Greggor et al. 2016).

Parental care theory predicts that individuals should invest into parental care depending on the value of existing offspring in relation to the cost of care to future offspring (Alonso-Alvarez and Velando 2012, Klug, et al. 2012). This decision depends in turn on the cues that parents receive regarding the value of current offspring and of future reproductive opportunities. According to the parental care theory, parents should invest more in larger broods than in smaller ones, while prioritizing future reproductive opportunities when broods are small and the prospect for future reproduction is good. This suggests that parental care could counteract negative densitydependent survival of offspring.

Over the lifetime of a parent, the balancing between present and future parental investment could cancel out the effect on total offspring production, as individuals that invest much early on may have less resources left to invest later on, and vice versa (Roff 1992). However, if the environment changes, the perception of the value of the current offspring, or of future reproductive opportunities, could change and the evolved rule of balancing become maladaptive. In particular, environmental change that alters female fecundity, such as changed food availability or 
temperature, could alter the number of offspring the parents care for and, thus, their perception of the value of current offspring. Parents that care for fewer offspring than expected could then reduce their investment into the offspring in the expectation of better future reproductive opportunities, and vice versa for parents that care for more offspring than expected. Such changes in parental investment could amplify the effect of altered female fecundity on offspring recruitment. In particular, reduced parental investment could amplify a negative effect of reduced female fecundity on offspring recruitment if parents do not receive more offspring later in life because of the environmental change (thus not benefitting from saving resources for future reproductive opportunities). Correspondingly, increased parental investment could amplify a positive effect of increased female fecundity on offspring recruitment, if parents are able to invest also in future offspring because of improved environmental conditions.

Human-induced environmental changes are currently altering the fecundity of females of many populations, through altered food availability, increased stress levels, higher temperature, and the presence of hormone-disrupting chemicals (Sokolova 2013, Soudijn et al. 2020, Watson et al. 2020). In the Baltic Sea, the lifetime fecundity of female threespine stickleback (Gasterosteus aculeatus) has increased during the last decades, in terms of number of egg clutches they produce during their lifetime, while the size of the egg clutches has not changed (Candolin and Voigt 2020). The increase in lifetime fecundity is probably caused by human-caused disturbances, eutrophication and global warming, as these allow females to produce egg clutches at shorter interspawning intervals (Hovel et al. 2017, Saarinen and Candolin 2020). Thus, more females are ready to spawn at any time point, which increases population fecundity (Candolin and Voigt 2020). The increased fecundity raises in turn the number of eggs males can collect in their nests - tunnel shaped constructions made out of algae and sand and built by the male. Males attempt to attract as many females as possible to spawn in their nests, to increase offspring production and possible their genetic diversity, and each female leaves immediately after spawning (Wootton 1984). Males switch to the parental care stage about 2 days after receiving the first clutch of eggs, after which they no longer court females. This is to ensure that all eggs are at the same developmental stage and require the same quality of parental care. Males care for the eggs by fanning fresh water into the nest, adjusting nest structure to the developmental stage of the embryos, and removing dead and diseased eggs (Candolin et al. 2008, Fox et al. 2018, Wootton 1984). 
The parental care stage lasts about two weeks, depending on water temperature, and males can complete several breeding cycles in succession (Candolin and Salesto 2006). However, parental care is costly in terms of time and energy and males have to balance between current and future parental investment in order to maximize lifetime reproductive success (Candolin 1998). Males may cannibalise the eggs when they receive few in order to start a new breeding cycle, and possibly to improve their body condition for future breeding cycles (Manica 2002).

Interestingly, the increase in the proportion of spawning females in the Baltic Sea correlates with the growth of the population during the last decades (Candolin and Voigt 2020). This suggests that the increased population fecundity has contributed to the growth of the population, alongside other changes in the environment, such as reduced predator abundance (Ljunggren et al. 2010). The survival of the eggs in the nests is expected to be negatively density dependent in the absence of parental care, as water quality inside nests deteriorates with egg number (Takegaki and Nakazono 1999, Takegaki and Nakazono 2000). However, increased parental investment of larger broods could counteract the negative density-dependence of egg survival and raise the number of offspring recruited into the population. This is plausible, as eutrophication has increased food availability (Candolin et al. 2016, Kraufvelin et al. 2006), and males consequently could have the resources needed to increase their investment into the offspring.

We investigated if changes in population fecundity in terms of number of eggs spawned into the nests of threespine stickleback influences parental investment and thus the number of offspring hatching. We allowed males to spawn with different numbers of females to receive different numbers of eggs, (i.e., egg density within the restricted space of the nest), and manipulated the presence of parental care. The males could complete two breeding cycles, as males in the investigated population usually complete two or three breeding cycles during a short single breeding season (Candolin 2000). These treatments allowed us to determine (1) if parental investment in the threespine stickleback is density-dependent in relation to number of eggs received, (2) if parental care alters the expected negative density-dependence of egg survival, and (3) the impact that parental care has on total offspring production over two breeding cycles when population fecundity changes.

\section{Materials and methods}


Housing and nest building

We caught adult threespine stickleback, age 2+, before the breeding season (early May) from a bay in the Baltic Sea $\left(59^{\circ} 50^{\prime} \mathrm{N}, 23^{\circ} 15^{\prime} \mathrm{E}\right), 2 \mathrm{~km}$ from Tvärminne Zoological Station in Southern Finland. We housed the fish in flow-through tanks at a density of 10 fish per 125 I tank, sexes separated. A lack of nesting material prevented males from building nests. We fed the fish defrosted chironomid larvae once a day. Males that came in reproductive condition within two week, based on nuptial coloration, were moved to individual flow-through tanks (10 I) to build nests on 'nesting dishes' (Candolin 1997). The tanks were kept at $15^{\circ} \mathrm{C}$ and a $18: 6$ light:dark regime. To stimulate nest building, we presented the males a gravid female enclosed in a transparent, perforated jar twice a day for $15 \mathrm{~min}$. In the experiment, we used only males that built a nest within two weeks and who cared for the nest through nest directed behaviours. We caught females throughout the breeding season for a steady supply of gravid females.

\section{Manipulation of egg number}

We allowed males with nests to spawn with 1, 2 or 4 females within one day, with a $1 \mathrm{~h}$ break between spawnings. We randomly assigned males to the three treatments, and females to the males. Females release all eggs ready to be laid during a spawning. We removed each female after spawning. If a female did not spawn within $20 \mathrm{~min}$, we replaced her with another female. Two males did not attract any females and we replaced them with new males. Males in the investigated population collect on average eggs from two females, and only about $5 \%$ of males receive eggs from four or more females; mean egg number in nests in the field is 221 (SD = 149, $N$ $=45)$ (Candolin 2004).

Two hours after a male had received the last clutch of eggs, when the eggs had hardened, we gently removed all eggs from the nest and weighed them to the nearest $0.01 \mathrm{~g}$ (Candolin 2000). We determined the percentage of eggs fertilized by inspecting 20 eggs - collected from different parts of the individual clutches - under a cold-light microscope. Cell divisions and the presence of yolk globules are clearly visible $2 \mathrm{~h}$ after fertilization. Male fertilization success was high (mean $99.5 \%, S D=1.5, N=60)$ and not significantly associated with total egg clutch size $\left(F_{1,58}=0.03, P=\right.$ 0.86). To determine the total number of eggs received, we divided the weight of all eggs with the mean weight of an egg. Mean egg weight was calculated by multiplying egg volume with egg 
density (buoyance), 1.01g/cm-3 (Nissling et al. 2017). To determine egg volume, we measured the diameter of the 20 inspected eggs, using a camera connected to the microscope (the egg is spherical). We did not round up or down the estimated number of eggs.

\section{Manipulation of parental care}

We randomly allocated the fertilized eggs to either a no care or a parental care treatment, ensuring equal number of replicates for each treatment (Fig. 1). In the no care treatment, the eggs developed at the bottom of a $10 \mathrm{I}$ tank in the absence of a nest and male care. A flow-through system combined with an air stone ensured high dissolved oxygen levels. When the eggs started to hatch, we stopped the flow-through system to prevent the water flow from washing out the offspring. We counted all hatched offspring 3 days post hatching. To assess survival after hatching - when the yolk sac had been absorbed and survival depended on external feeding - we transferred 20 offspring to clean flow-through tanks (10 I). We fed the offspring fluid artemia solution (JBL NobilFluid artemia), and removed dead individuals daily. We recorded survival 7 days post hatching.

We returned the eggs in the parental care treatment to the nest and male parental care within 10 min from being removed from the nest. Removing and returning eggs do not influence male parental care or egg mortality (Candolin 2000). We did not feed the males during parental care, as they usually do not feed when parenting (Wootton 1984). The tanks were kept under similar conditions as the tanks in the no care treatment. We measured male fanning activity daily during $10 \mathrm{~min}$ by measuring the time the male spent at the nest entrance fanning fresh water into the nest (Candolin, et al. 2008). The parental phase lasts about 10 days under the selected temperature. When the eggs started to hatch and fry were visible at the nest entrance, we stopped the flow-through system and moved the male to another $10 \mathrm{I}$ tank with similar conditions, to prevent him from cannibalising the offspring when they left the nest (in nature, offspring escape cannibalism by moving away from the nest). When all offspring had left the nest, we checked the nest for the presence of any undeveloped or dead eggs, and returned the nesting dish to the male in his new tank. We counted all hatched offspring 3 days post hatching, and recorded survival 7 days post hatching, using the same methods as in the no care treatment. 


\section{Success across breeding cycles}

We allowed the males in the parental care treatment to complete a second breeding cycle (Fig. 1). When the males had reconstructed the nest, which is needed to start a new breeding cycle, and resumed normal courtship behaviour, we allowed them to spawn with the same number of females as during the first breeding cycle (1, 2 or 4 females), and to perform parental care under the same conditions. Male fertilization success was again high (mean 99.3\%, SD =1.7, N = 30) and not significantly associated with egg number $\left(F_{1,28}=0.24, P=0.63\right)$. We recorded fanning activity, hatching success, and survival 7 days post hatching using similar methods as during the first breeding cycle.

One male did not enter a second breeding cycle and one male did not survive the second cycle. These males did not differ from the other males in body length (Mann Whitney $U=88, P=0.31$ ) or condition (Fulton's condition factor, $\mathrm{U}=75, \mathrm{P}=0.58$ ) at the start of the experiment.

\section{Analyses}

The analyses were carried out with the two males that did not enter or survive the second breeding cycle first included and then excluded. Qualitatively similar results were gained and we present the results with the two males excluded. The analyses are based on number of eggs received, not number of females spawning, as females vary in the number of eggs they carry. To analyse if parental investment was density-dependent in relation to egg number, we calculated the mean time spent fanning per parental care day, and used least squares regression to relate fanning activity to egg number.

To analyse if parental care alters density-dependent hatching success (proportion of eggs hatching) and offspring survival during the first breeding cycle, we used linear least squares (LS) regression with presence of parental care and egg number as determinants. We added polynomial terms of egg number to the model to test if the relationship with hatching success was curvilinear. To test if the probability of whole egg clutch cannibalism depended on egg number, we used logistic regression with egg number as covariate.

To analyse the influence of egg number on changes in hatching success from the first to the second breeding cycle, we used a mixed model with male as random factor and egg number as 
covariate and the order of the cycle as fixed factors. To analyse the influence of egg number on total hatching success over the two breeding cycles, we used a weighted LS regression - as the variation in hatching success decreased with egg number - with the percentage of all eggs hatching as the dependent variable and the total number of eggs received as the covariate. The assumptions of the tests were checked before analyses and all analyses were performed using the software IBM SPSS Statistics 25 . The models and full estimates are given in the supporting information.

\section{Results}

First breeding cycle

Parental investment was density-dependent in relation to number of eggs in the nests, as time spent fanning increased with egg number (the three males that did not hatch any offspring were excluded from the analysis; $F_{1,25}=13.46, P=0.001$, Table S1).

Parental care reversed negative density-dependent hatching success, as hatching success was negatively related to egg number in the absence of parental care, and positively related in the presence of parental care (interaction between parental care and egg number: $F_{1,56}=32.04, P<$ 0.001 , Fig. 2, Table S2). Adding a quadratic term for egg number and its interaction with parental care, to test for a curvilinear relationship, did not improve the fit of the model based on Akaike information criterion, AIC. Hatching success was higher in the absence of care $\left(F_{1,56}=79.07, P<\right.$ 0.001 , Fig. 2, Table S2). The absolute number of hatched eggs increased with egg number, and more steeply in the presence than in the absence of care: the number of hatched offspring was lower when egg number was low, and higher when egg number was high, in the presence of care (interaction between parental care and egg number: $F_{1,56}=4.93, P=0.030$, Fig. 3, Table S3).

Adding a quadratic term for egg number and its interaction with parental care did not improve the fit of the model based on AIC.

No undeveloped eggs were found in the nests. This indicates that eggs that did not hatch had been cannibalised. Whether the eggs were dead or alive when cannibalised is unknown. Three males cannibalised all eggs. These males had spawned with one female and received fewer eggs than males that hatched offspring (logistic regression, Wald $=13.04, P<0.001$ ). They did not perform 
any fanning behaviour, which indicates that they cannibalised the eggs before entering the parental care stage.

The survival of the offspring 7 days post hatching did not depend on egg number $\left(F_{1,54}=0.06, P=\right.$ 0.80 ) or presence of parental care $\left(F_{1,54}=0.39, P=0.53\right.$, Table $\left.S 4\right)$.

\section{Second breeding cycle of parental males}

Parental investment continued to be positively density-dependent during the second breeding cycle, as time spent fanning increased with egg number $\left(F_{1,28}=42.56, P<0.001\right.$, Table S5). Thus, hatching success continued to increase with egg number $\left(r^{2}=0.18, b=0.02, \mathrm{SE}=0.01, \mathrm{~F}_{1,28}=6.36\right.$, $P=0.018$, Table S6). Hatching success was higher during the second cycle than the first cycle $\left(F_{1,29}\right.$ $=9.15, P=0.005$, Fig. 2, Table S7). Males with few eggs improved their hatching success more than males with many eggs (interaction between egg number and order of cycle: $F_{1,34}=9.66, P=0.004$, Figure 2, Table S8). Offspring survival 7 days post hatching did not depend on egg number $\left(\mathrm{F}_{1,28}=\right.$ $0.69, \mathrm{P}=0.41$, Table S9).

Across the two breeding cycles, males that received many eggs had a higher total hatching success than males that received few eggs $\left(F_{1,28}=20.33, P<0.001\right.$, Fig. 4 , Table S10). This holds also when the three males that cannibalised all eggs are removed from the analysis $\left(F_{1,25}=15.52, P=0.001\right)$. These males could have been able to restart the breeding cycle earlier - as we did not know when the eggs were cannibalised - and lost less time than in the present experiment. The absolute number of unhatched eggs increased with egg number during both the first $\left(F_{1,28}=42.00, P<\right.$ 0.001 , Table S11) and the second breeding cycle $\left(F_{1,28}=67,74, P<0.001\right.$, Table S12).

\section{Discussion}

Our results show that male parental care counteracts negative density-dependent egg hatching success in the nest-brooding threespine stickleback. This indicates that male parental care can reverse negative density-dependent recruitment of offspring into populations, with potential consequences for their structure and dynamics. The impact is especially likely when population fecundity is altered because of environmental disturbances, such as eutrophication or climate change, as the optimal balancing between present and future parental investment can then be 
disrupted. This can amplify the effect of altered fecundity on offspring production, by reducing the number of offspring hatching when fecundity decreases, and raising the number when fecundity increases.

The cause of the positive density-dependent hatching success of stickleback males was increased investment in parental care when receiving many eggs, while often cannibalising the eggs, sometimes all eggs, when receiving few. Caring for a few eggs is costly in terms of time and energy, and cannibalising part of them can both save and provide energy for future reproductive opportunities. Cannibalising all eggs can in turn allow males to start a new breeding cycle (as more eggs cannot be added when the existing ones are a few days old). However, better reproductive opportunities may not arise if population fecundity has dropped, in which case whole clutch cannibalism becomes a risky strategy.

Later in the season, during the second breeding cycle, males increased their investment into parental care, particularly males that received few eggs during both breeding cycles. The increased investment was probably a response to declining future reproductive opportunities, as most individuals can complete only one breeding season (Candolin 2000). Yet, males that received few eggs continued to hatch a lower percentage of them than males that received many eggs. These males were probably still saving resources for future reproductive opportunities, although such opportunities may not arise when population fecundity has declined. Thus, across the two breeding cycles, the relationship between total number of eggs received and total hatching success was positive, i.e., positive density-dependent hatching success. These results indicate that altered population fecundity can reduce the adaptedness of the balancing between present and future parental investments, especially when fecundity drops because of environmental disturbances, and change offspring recruitment. The results also hold when the males that cannibalised all eggs during the first breeding cycle are deleted from the analysis. These males could have been able to restart a breeding cycle faster than was possible in the experiment and consequently lost less time and had a higher reproductive success than here recorded.

Interestingly, hatching success was lower for eggs that developed inside nests under parental care than for eggs that developed outside nests in the absence of care. Apparently, males were not able to make up for the negative effect that nest structure has on water exchange and thus on water quality (Takegaki and Nakazono 1999, Takegaki and Nakazono 2000). This indicates that while nest brooding decreases predation risk on eggs, it bears a cost in terms of reduced hatching 10 
success. Males may have cannibalised some of the eggs to ensure that the remaining eggs received the oxygen needed for development (Klug et al. 2006, Payne et al. 2002). Thus, the absolute number of unhatched (cannibalised) eggs increased with egg number. These results also indicate that males do not cannibalise a constant number of eggs, but adjust it to their abundance. Whether these experimental results can be extrapolated to conditions in the field depends on a range of factors. Males may be able to assess changes in current reproductive opportunities under natural conditions, through the rate at which females approach their nests, and alter the allocation of parental investment accordingly. However, males are less likely to correctly assess changes in future reproductive opportunities. Male condition could also change in parallel with female fecundity, particularly if the cause of the fecundity change is altered food availability. This could influence the number of breeding cycles that males can complete and, thus, their balancing between present and future parental investment. Males in poorer condition may increase their investment into the first breeding cycle, because of fewer future reproductive opportunities (Candolin 1999, Candolin 2000), which could reduce the negative effect of decreased population fecundity on offspring recruitment, while males in better condition could complete more breeding cycles, which could amplify an effect of increased female fecundity on offspring production. The latter scenario could have contributed to the growth of the stickleback population in the Baltic Sea, which is currently having negative effects on the ecosystem through increased predation on early life stages of coastal predatory fishes and by altering species interactions (Bergström et al. 2015, Candolin et al. 2016, Candolin and Voigt 2020, Jakubaviciute and Candolin 2021). However, the ultimate effect of the increased offspring production on the population depends on processes after hatching that influence survival, such as competition for resources and risk of predation and infections (Murdoch 1994, Rose, et al. 2001). These could restore negative density-dependent recruitment. More research is needed on these processes to determine the ultimate effect of increased offspring production on population growth.

The generality of our findings across species and taxa is unknown. Environmental changes often disrupt behaviours from their optimum expression (Sih, et al. 2011, Tuomainen and Candolin 2011), and similar pattern to the detected one could occur in other species where fecundity is altered and parents misjudge the opportunities of future reproductive opportunities and, thus, the optimal allocation between present and future parental investment. While positively densitydependent parental investment may be beneficial in populations with increased fecundity, the 11 
effect could be detrimental in declining populations. Thus, attention should be given to parental care behaviours in populations with changing dynamics to determine the degree to which altered parental investment has contributed to changes in dynamics. Such knowledge can inform us of the actions needed to mitigate negative effects of environmental disturbances on populations. Research is also needed on which species are likely to maladaptively adjust their parental investment to changes in population fecundity, and under which ecological conditions, and if the likelihood depends on whether the species has maternal, paternal or biparental care.

To conclude, our results show that positive density-dependent parental care can amplify the effect of altered population fecundity on offspring production. In particular, reduced fecundity can cause the balancing between present and future parental investment to become maladaptive and further reduce offspring production, while increased fecundity can increase investment into parental care and promote offspring production and population growth. At a broader level, our results stress the importance of considering individual behaviours when evaluating the effects of human-induced environmental disturbances on populations. Individual behaviours have evolved to maximize individual fitness under local conditions, but can become maladaptive when the environment changes, which can influence population processes (Anthony and Blumstein 2000, Frank 2010). Yet, individual behaviours are seldom considered when investigating population dynamics in disturbed environments, although improved knowledge of these can reveal causes and mechanisms behind altered population dynamics, which in turn can enhance our ability to predict, and possibly mitigate, human-induced ecological changes (Blumstein and FernandezJuricic 2010, Candolin and Wong 2012, Greggor, et al. 2016).

\section{Speculations}

What is the contribution of altered offspring production to changes in population dynamics? The effect depends on the number of offspring produced, as juvenile mortality is higher in species with larger broods. In the threespine stickleback, a female usually produces 100-150 eggs per clutch and she may produce up to 5 clutches over her lifetime (Saarinen and Candolin 2020). Thus, juvenile mortality is high in the species and changes in number of hatched offspring may not have a decisive influence on population dynamics. However, in species with lower fecundity, even slight changes in offspring production caused by altered parental investment could have profound 
implications for populations dynamics. Thus, the impact that human-induced disturbances have on parental care behaviour and thereby on offspring production should be especially investigated in these species.

\section{Literature cited}

Alonso-Alvarez, C. and Velando, A. 2012. Benefits and costs of parental care. - In: Royle, N. J., et al. (eds.), Evolution of Parental Care. Oxford Univ Press, pp. 40-61.

Anthony, L. L. and Blumstein, D. T. 2000. Integrating behaviour into wildlife conservation: the multiple ways that behaviour can reduce N-e. - Biol. Conser. 95: 303-315.

Bergström, U., Olsson, J., Casini, M., Eriksson, B. K., Fredriksson, R., Wennhage, H. and Appelberg, M. 2015. Stickleback increase in the Baltic Sea - A thorny issue for coastal predatory fish. - Estuar. Coast. Shelf Sci. 163: 134-142.

Blumstein, D. T. and Fernandez-Juricic, E. 2010. Primer of Conservation Behavior. - Sinauer Assoc.

Candolin, U. 1997. Predation risk affects courtship and attractiveness of competing threespine stickleback males. - Behav. Ecol. Sociobiol. 41: 81-87.

Candolin, U. 1998. Reproduction under predation risk and the trade-off between current and future reproduction in the threespine stickleback. - Proc. R. Soc. Lond. B 265: 1171-1175.

Candolin, U. 1999. The relationship between signal quality and physical condition: is sexual signalling honest in the three-spined stickleback? - Anim. Behav. 58: 1261-1267.

Candolin, U. 2000. Changes in expression and honesty of sexual signalling over the reproductive lifetime of sticklebacks. - Proc. R. Soc. Lond. B 267: 2425-2430.

Candolin, U. 2000. Increased signalling effort when survival prospects decrease: male-male competition ensures honesty. - Anim. Behav. 60: 417-422.

Candolin, U. 2004. Effects of algae cover on egg acquisition in male three-spined stickleback. - Behaviour 141: 1389-1399. 
Candolin, U., Engström-Öst, J. and Salesto, T. 2008. Human-induced eutrophication enhances reproductive success through effects on parenting ability in sticklebacks. - Oikos 117: 459-465.

Candolin, U., Johanson, A. and Budria, A. 2016. The influence of stickleback on the accumulation of primary production: a comparison of field and experimental data. - Estuaries Coasts 39: 248-257.

Candolin, U. and Salesto, T. 2006. Effects of increased vegetation cover on nesting behavior of sticklebacks (Gasterosteus aculeatus). - Behav. Ecol. Sociobiol. 59: 689-693.

Candolin, U., Tukiainen, I. and Bertell, E. 2016. Environmental change disrupts communication and sexual selection in a stickleback population. - Ecology 97: 969-979.

Candolin, U. and Voigt, H. R. 2020. Population growth correlates with increased fecundity in three-spined stickleback populations in a human-disturbed environment. - Aquat. Sci. 82: 21.

Candolin, U. and Wong, B. B. M. 2012. Behavioural responses to a changing world. Mechanisms and consequences. - Oxford University Press.

Fox, R. J., Head, M. L. and Barber, I. 2018. Good parenting may not increase reproductive success under environmental extremes. - J. Evol. Biol. 31: 1638-1646.

Frank, S. A. 2010. Demography and the tragedy of the commons. - J. Evol. Biol. 23: 32-39.

Greggor, A. L., Berger-Tal, O., Blumstein, D. T., Angeloni, L., Bessa-Gomes, C., Blackwell, B. F., St Clair, C. C., Crooks, K., de Silva, S., Fernandez-Juricic, E., Goldenberg, S. Z., Mesnick, S. L., Owen, M., Price, C. J., Saltz, D., Schell, C. J., Suarez, A. V., Swaisgood, R. R., Winchell, C. S. and Sutherland, W. J. 2016. Research Priorities from Animal Behaviour for Maximising Conservation Progress. - Trends Ecol. Evol. 31: 953-964.

Hovel, R. A., Carlson, S. M. and Quinn, T. P. 2017. Climate change alters the reproductive phenology and investment of a lacustrine fish, the three-spine stickleback. - Glob. Change Biol. 23: 2308-2320.

Jakubaviciute, E. and Candolin, U. 2021. Density-dependent behavioural interactions influence coexistence between a native and a non-native mesopredator. - Biol. Invasions.

Klug, H., Alonzo, S. H. and Bonsall, M. B. 2012. Theoretical foundations of parental care. - In: Royle, N. J., et al. (eds.), Evolution of Parental Care. Oxford Univ Press, pp. 21-39. 
Klug, H., Lindström, K. and St Mary, C. M. S. 2006. Parents benefit from eating offspring: Density-dependent egg survivorship compensates for filial cannibalism. - Evolution 60: 2087-2095.

Kraufvelin, P., Salovius, S., Christie, H., Moy, F. E., Karez, R. and Pedersen, M. F. 2006. Eutrophicationinduced changes in benthic algae affect the behaviour and fitness of the marine amphipod Gammarus locusta. - Aquat. Bot. 84: 199-209.

Ljunggren, L., Sandström, A., Bergström, U., Mattila, J., Lappalainen, A., Johansson, G., Sundblad, G., Casini, M., Kaljuste, O. and Eriksson, B. K. 2010. Recruitment failure of coastal predatory fish in the Baltic Sea coincident with an offshore ecosystem regime shift. - ICES J. Mar. Sci. 67: 1587-1595.

Manica, A. 2002. Filial cannibalism in teleost fish. - Biol. Rev. 77: 261-277.

Murdoch, W. W. 1994. Population regulation in theory and practice. - Ecology 75: 271-287.

Nissling, A., Nyberg, S. and Petereit, C. 2017. Egg buoyancy of flounder, Platichthys flesus, in the Baltic Seaadaptation to salinity and implications for egg survival. - Fish Res. 191: 179-189.

Payne, A. G., Smith, C. and Campbell, A. C. 2002. Filial cannibalism improves survival and development of beaugregory damselfish embryos. - Proc. R. Soc. Lond. B. 269: 2095-2102.

Ratikainen, II, Haaland, T. R. and Wright, J. 2018. Differential allocation of parental investment and the trade-off between size and number of offspring. - Proc. R. Soc. Lond. B 285: 9.

Roff, D. 1992. The evolution of life-histories. - Chapman and Hall.

Rose, K. A., Cowan, J. H., Winemiller, K. O., Myers, R. A. and Hilborn, R. 2001. Compensatory density dependence in fish populations: importance, controversy, understanding and prognosis. - Fish. Fish. 2: 293-327.

Saarinen, A. and Candolin, U. 2020. Mechanisms behind bottom-up effects: eutrophication increases fecundity by shortening the interspawning interval in stickleback. - PeerJ 8: 14.

Sih, A., Ferrari, M. C. O. and Harris, D. J. 2011. Evolution and behavioural responses to human-induced rapid environmental change. - Evol. Appl. 4: 367-387.

Sokolova, I. M. 2013. Energy-Limited Tolerance to Stress as a Conceptual Framework to Integrate the Effects of Multiple Stressors. - Integrative and Comparative Biology 53: 597-608. 
Soudijn, F. H., van Kooten, T., Slabbekoorn, H. and de Roos, A. M. 2020. Population-level effects of acoustic disturbance in Atlantic cod: a size-structured analysis based on energy budgets. - Proc. R. Soc. Lond. B 287: 9.

Takegaki, T. and Nakazono, A. 1999. Responses of the egg-tending gobiid fish Valenciennea longipinnis to the fluctuation of dissolved oxygen in the burrow. - Bull. Mar. Sci. 65: 815-823.

Takegaki, T. and Nakazono, A. 2000. The role of mounds in promoting water-exchange in the egg-tending burrows of monogamous goby, Valenciennea longipinnis (Lay et Bennett). - J. Exp. Mar. Biol. Ecol. 253: 149-163.

Tuomainen, U. and Candolin, U. 2011. Behavioural responses to human-induced environmental change. Biol. Rev. 86: 640-657.

Turchin, P. 1995. Population regulation: old arguments and a new synthesis. - In: Cappuccino, N. and Price, P. (eds.), Population dynamics. Academic Press, pp. 19-40.

Watson, J. W., Hyder, K., Boyd, R., Thorpe, R., Weltersbach, M. S., Ferter, K., Cooke, S. J., Roy, S. and Sibly, R. M. 2020. Assessing the sublethal impacts of anthropogenic stressors on fish: An energy-budget approach. - Fish. Fish. 21: 1034-1045.

Wootton, R. J. 1984. The functional biology of sticklebacks. - Croom Helm. 


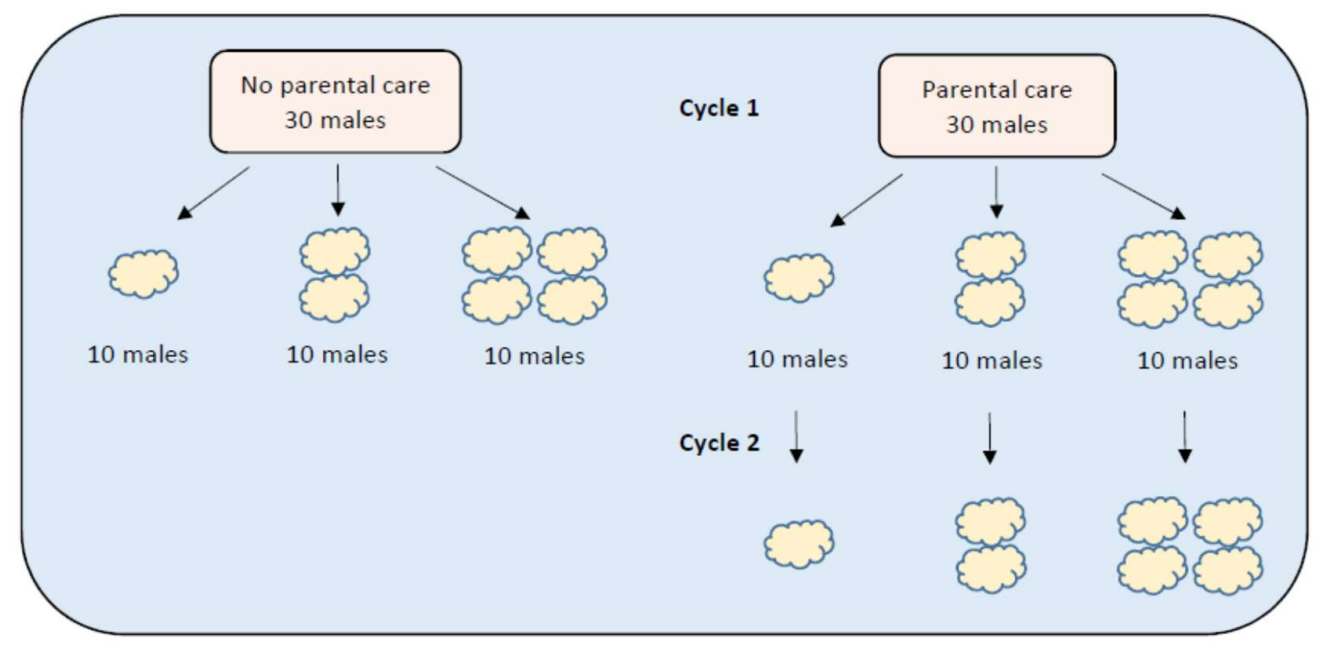

Fig. 1. Experimental design with 60 males spawning with 1, 2, or 4 females to gain different numbers of eggs. The eggs were raised in the absence or presence of parental care (30 males in each treatment). Parental males went through a second breeding cycle during which they spawned with the same number of females. 


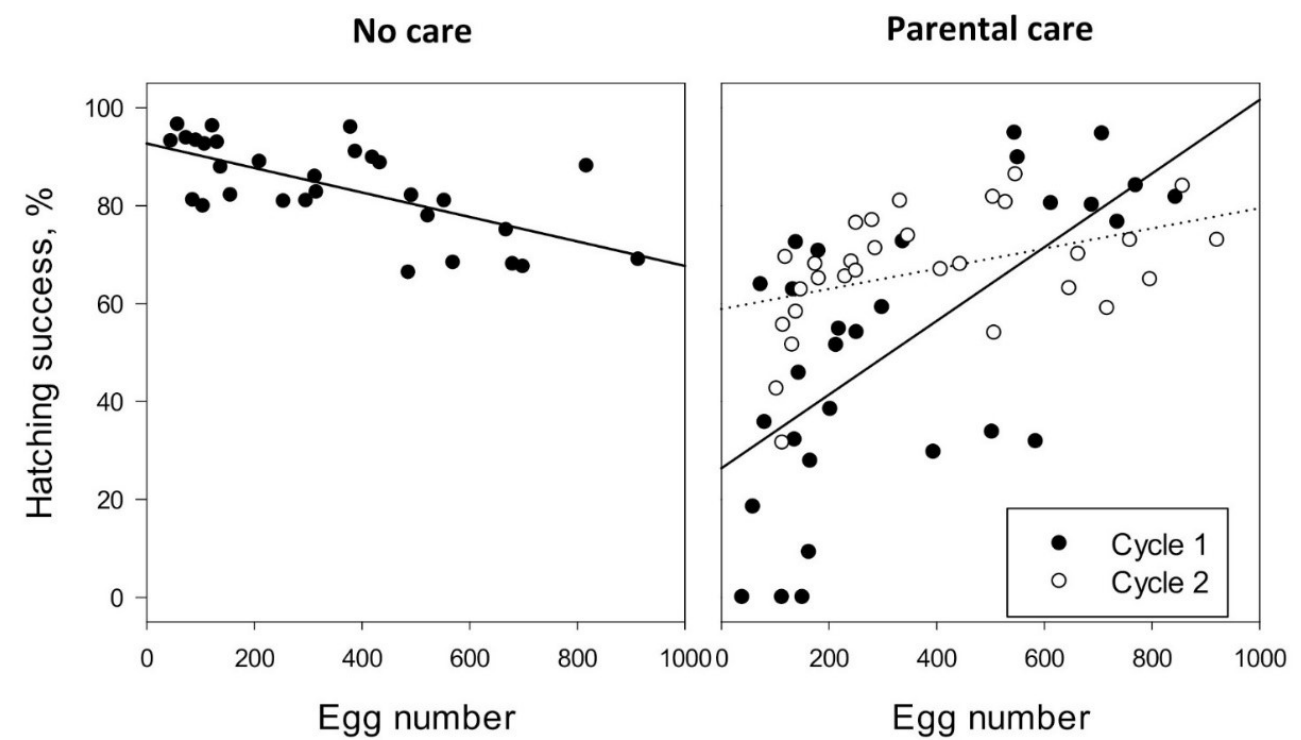

Fig. 2. Hatching success in relation to egg number in nests in the absence of parental care (least squares regression: $\left.r^{2}=0.44, b=-0.025, S E=0.005\right)$ and in the presence of parental care during the first breeding cycle $\left(r^{2}=0.42, b=0.08, \mathrm{SE}=0.02\right)$ and the second breeding cycle $\left(r^{2}=0.19, b=\right.$ $0.02, \mathrm{SE}=0.01)$. 


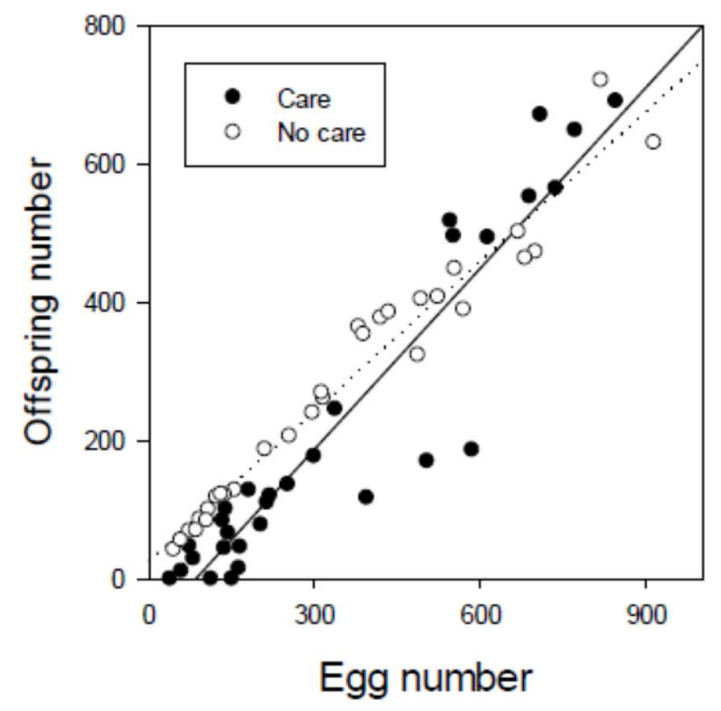

Fig. 3. The dependence of number of offspring hatching on number of eggs received during the first breeding cycle in the absence (least squares regression: $r^{2}=0.96, b=0.72, S E=0.03$ ) and presence of parental care $\left(r^{2}=0.88, b=0.87, \mathrm{SE}=0.06\right)$. 


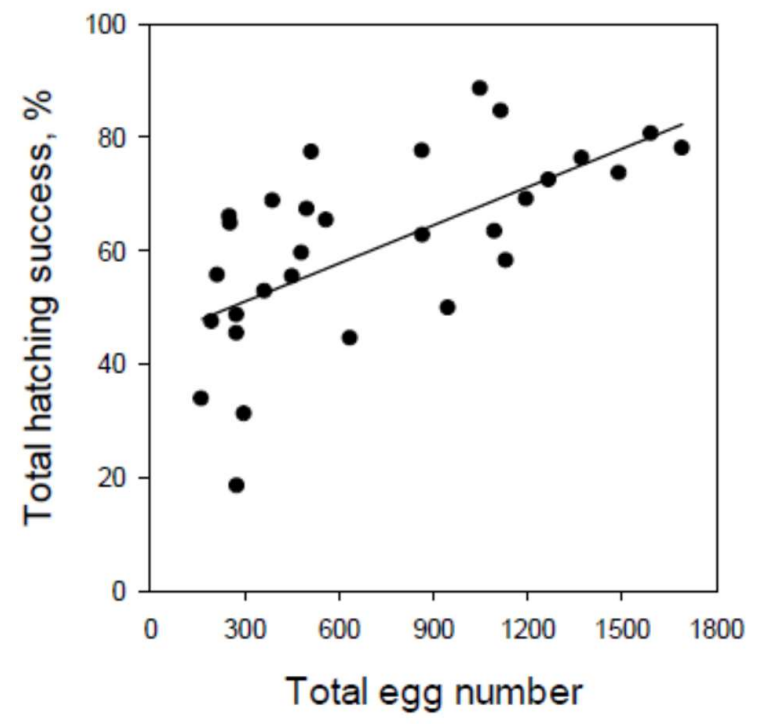

Figure 4. The dependence of hatching success of parenting males on total number of eggs received across the two breeding cycles (weighed least squares regression: $r^{2}=0.42, b<0.01, \mathrm{SE}<0.01$ ). 